\begin{tabular}{|l|lll|}
\hline & \multicolumn{3}{|c|}{ PORT-SAID ENGINEERING RESEARCH JOURNAL } \\
\hline
\end{tabular}

\title{
Sensor and Sensorless Speed Control of Doubly Fed Induction Generator Wind Turbines for Maximum Power Point Tracking
}

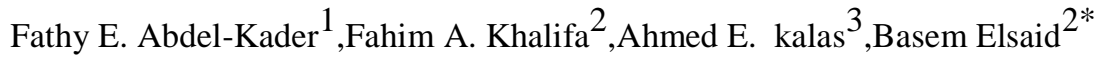

\begin{abstract}
Wind turbine output power can be maximized using maximum power point tracking (MPPT). By estimating wind speed, the MPPT can be achieved easily by adjusting the speed of DFIG based wind turbine through back-to-back converter. The grid side unity power factor can be simply achieved using PI controller on hybrid inverter. The aerodynamic power captured by wind turbine is the cosine function of pitch angle. In this paper, the pitch angle is kept zero, which is a valid assumption for lower to medium wind velocities. The machine side converter (MSC) is used to track the maximum power point for different wind speed. The grid side converter (GSC) uses a vector current controller to supply power at unity power factor to the grid. The simulations have been performed using MATALB/SIMULINK. The effectiveness of proposed control methods validated.
\end{abstract}

Keywords-Maximum PowerPoint Tracking (MPPT), Doubly Fed Induction Generator (DFIG), Variable speed wind turbine (VSWT), Wind energy.

\section{INTRODUCTION}

Wind power is today's fastest growing renewable energy source. A wind turbine operates either at a fixed or variable speed rate [1]. Most of wind turbine manufacturers are developing new megawatt scale wind turbines based on variable-speed operation with pitch control using a doubly fed induction generator (DFIG) [2-4].

The variable speed wind turbine with DFIG and fullscale/fully controllable voltage source converters (VSCs) is considered to be a promising, but not yet very popular, wind turbine concept [3]. The wind turbines based on DFIG configuration have many advantages such as gearless construction [4], elimination of a dc excitation system [1-5].

\footnotetext{
${ }^{1}$ Electrical Engineering Department Faculty of Engineering ,Monofia University, Monofia, Egypt., E-mail:

fatkader2@yahoo.com

${ }^{2}$ Electrical Engineering , Faculty of Engineering, Suez Canal University, Ismailia, Egypt,E-mail:

Basem_elhady@yahoo.com

${ }^{3}$ Electrical Engineering , Faculty of Engineering 2 Port Said University,

Port Said, Egypt,E-mail:

kalas14@yahoo.com
}

Full controllability of the system for maximum wind power extraction and grid interface, and ease in accomplishing fault-ride through and grid support [6].Therefore, the efficiency and reliability of a VSCbased DFIG wind turbine is assessed to be higher than that based DFIG [7]. Maximum power point tracking control in most of the conversion systems is implemented using wind speed data obtained from wind speed sensors [9-12]. However, accurate measurement of wind speed is not easy especially in case of large size wind turbines. Anemometer installed on the top of nacelle provides limited measurements of wind speed only at the hub height and cannot cover the whole span of large blades [13-15].

Due to the interaction between the rotor and the wind, anemometer, usually placed on nacelles, leads to inaccurate wind speed measurements in both upwind and downwind turbines. Therefore, Speed control of wind turbine based on sensor less algorithms has gained much interests due to its accuracy and simplicity in tracking the maximum power point during wind speed variations. 
Doubly fed induction generator (DFIG) has been widely used for large-scale wind power generation systems due to its advantages, such as variable speed operation, controllable power factor and improved system efficiency [3].The amount of energy extracted from the wind depends not only on the incident wind speed, but also on the control system applied on the wind energy conversion system (WECS). Typically, maximum wind power extraction is accomplished by using fully controlled variable speed wind turbine generators. The rotational speed of wind turbine hub is adjusted according to the incident wind speed to track the maximum wind power trajectory [1], [4].

In this paper, maximum power point tracking for wind turbine based DFIG has been achieved by wind velocity estimation technique. Estimation of the windvelocitywasmade considering the relation between the system efficiency and the injected power to the grid. A full scale power converter based five-phase has been used. The dc-link, connecting the back-to-back converters, allow fully decoupled control of DFIG from the grid side. The MPPT has been achieved by controlling the DFIG speed at the generator side, whereas the grid side converter has been controlled to achieve unity power factor at the grid side. The effectiveness of the proposed control technique in addition to the efficient operation of the wind turbine system based onDFIG has been verified using Matlab/Simulink.

\section{SYSTEM MODELING}

Wind Energy Conversion System (WECS) converts kinetic energy of the wind to mechanical energy by means of wind turbine rotor blades then the generator converts the mechanical power to electrical power that is being fed to the grid through power electronic converters. The WECS under study, describedin Fig. 1, consistsof two main parts: a) Mechanical parts: include the aerodynamic system with the rotor blades. b) Electrical parts: comprised of the DFIG and the back-to-back converter set [2], and [5-6].

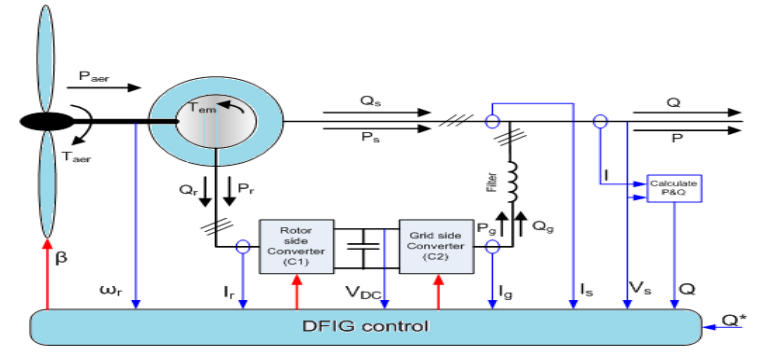

Fig.1: Power flow and control diagram of DFIG [5].
The aerodynamic rotor is responsible for converting wind power incident on turbine rotor blades which rotate with swept area $\left(A=\pi R^{2}\right)$, to mechanical power form. The mechanical power is given as follows:

$$
P_{m}=\frac{1}{2} C_{p} \rho \pi R^{2} V_{w i n d}^{3}
$$

Where; $\rho$ is the air density $\left(\mathrm{Kg} / \mathrm{m}^{3}\right), \mathrm{R}$ is the blade length $(\mathrm{m}), \mathrm{V}_{\text {wind }}$ is wind speed $(\mathrm{m} / \mathrm{s})$ and $\mathrm{C}_{\mathrm{p}}$ is the power coefficient. The value of $C_{p}$ is dependent on the tip speed ratio $(\lambda)$ and the blades pitch angle $(\beta)$. The blades pitch angle is adjusted by the embedded pitch controllers and depends on the type and operating condition of the wind turbine. The mathematical expression of $\mathrm{C}_{\mathrm{p}}$ is given by [1], [5] and [7] as;

$$
C_{p}=c_{1}\left(\frac{c_{2}}{\lambda_{i}}-c_{3} \beta-c_{4}\right) e^{\frac{-c_{5}}{\lambda_{i}}}+c_{6} \lambda
$$

The parameters $\lambda \mathrm{i}$ and $\mathrm{c} 1-\mathrm{c} 6$ are defined in the Appendix [6]. The tip speed ratio is given as follows:

$$
\lambda=\frac{\omega_{t} R}{V_{\text {wind }}}
$$

where: $\omega \mathrm{t}(\mathrm{rad} / \mathrm{s})$ is the rotational speed of the turbine shaft. The mechanical input torque, Tm, is given as follows:

$$
T_{m}=\frac{p_{m}}{\omega_{t}}
$$

Fig.2 shows the relation between $\mathrm{Cp}$ and $\lambda$ for different pitch angles. The maximum value of the power coefficient, $\mathrm{Cp}$ _max $\approx 0.48$, is obtained at $\beta$ $=0^{\circ}$ and $\lambda=\lambda$ opt $\approx 8.1$. Fig. 3 describes the wind turbine output power characteristics. Based on Fig.3, for any particular wind speed, there is optimum rotational speed, which gives the maximum power capturing.

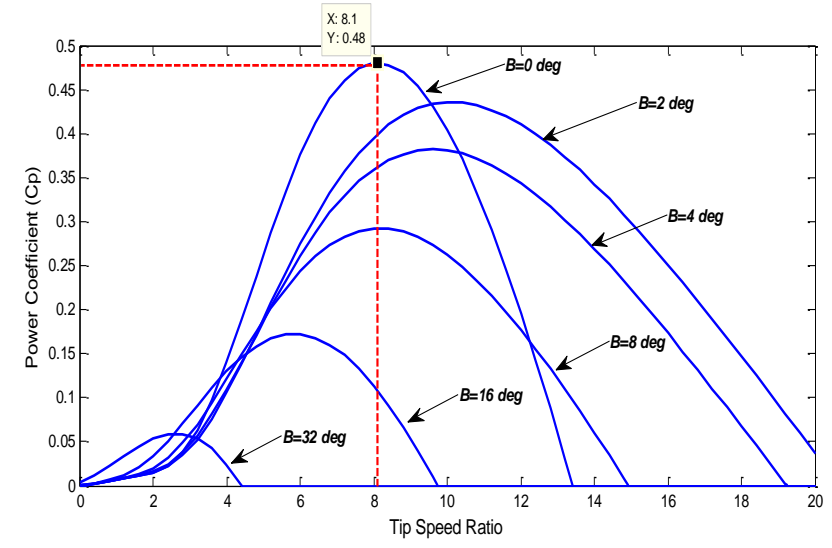

Fig. 2: $\mathrm{Cp} / \lambda$ curves for different values of the pitch angle, $\beta$.

\section{A. Mechanical Part Representation}




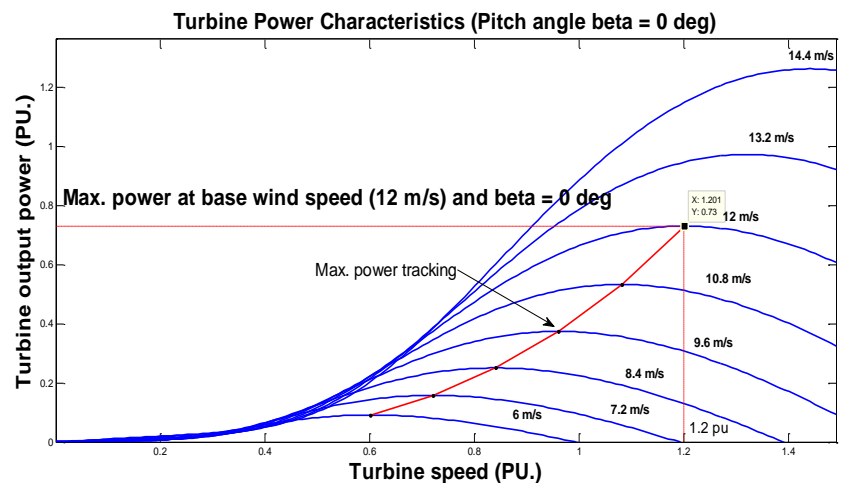

Fig. 3: The power characteristics of the wind turbine used.

\section{B. Electrical Part Representation}

As shown in Fig. 1, variable speed wind turbine DFIG is connected directly to the utility grid through the stator. The rotor is connected via a back-to-back set of converters. The first converter, known as the rotor side converter, is connected to the rotor windings of the DFIG. While the other one is known as grid side converter and is connected to the grid at the PCC via ac filter. The $\mathrm{dc}$ terminals of the two converters are collected together with shunt dc capacitor. DFIG model with detailed description along with the control schemes of the interfacing converters are presented in MATLAB/SIMULINK environment as in [3] and [5].

\section{B.1 Modeling of DFIG}

The mathematical model of the DFIG presented in this paper uses the $\mathrm{d}-\mathrm{q}$ synchronous reference frame illustrated inFig.4.

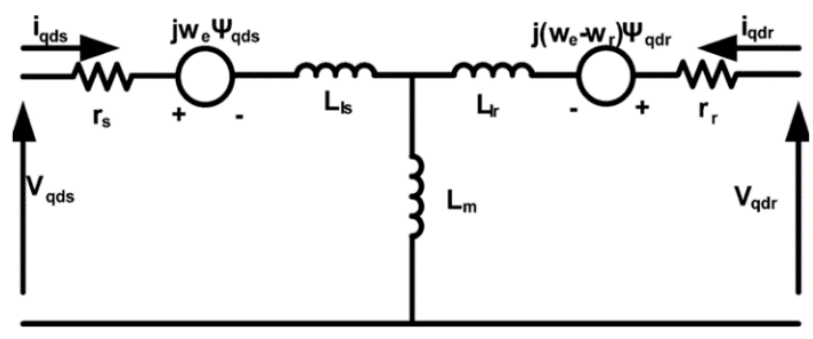

Fig. 4: Doubly fed induction generator model.

The d-q synchronous reference frame equations of the stator and rotor flux are written as[3], [8] and [9]:

$V_{q s}=R_{s} i_{q s}+\frac{d}{d t} \varphi_{q s}+\omega \varphi_{d s}$
$V_{d s}=R_{s} i_{d s}+\frac{d}{d t} \varphi_{d s}-\omega(6)$
$V_{q r}^{\prime}=R_{r}^{\prime} i_{q r}^{\prime}+\frac{d}{d t} \varphi_{q r}^{\prime}+\left(\omega-\omega_{r)} \varphi_{d r}^{\prime}\right.$
$V_{d r}^{\prime}=R^{\prime}{ }_{r} i_{d r}^{\prime}+\frac{d}{d t} \varphi_{q r}^{\prime}-\left(\omega-\omega_{r)} \varphi_{q r}^{\prime}\right.$
$\varphi_{q s}=L_{s *} i_{q s}+L_{m *} i_{q r}^{\prime}(9)$
$\varphi_{d s}=L_{s} i_{d s}+L_{m} i_{d r}^{\prime}$ $\varphi_{q r}^{\prime}=L_{r}^{\prime} i_{q r}^{\prime}+L_{m} i_{q s}(11)$

$\varphi_{d r}^{\prime}=L_{r}^{\prime} i_{d r}^{\prime}+L_{m} i_{d s}(12)$

$L_{s}=L_{l s}+L_{m}(13)$

$L_{r}^{\prime}=L_{l r}^{\prime}+L_{m}(14)$

The active and reactive power equations at the stator and rotor windings are written as:

$P_{s}=V_{d s} i_{d s}+V_{q s} i_{q s}$
$Q_{s}=V_{q s} i_{d s}-V_{d s} i_{q s}$

$Q_{s}=V_{q s} i_{d s}-V_{d s} i_{q s}$

$P_{r}=V_{q r} i_{d r}+V_{q r} i_{q r}$

$Q_{r}=V_{d r} i_{d r}-V_{d r} i_{q r}$

The electromagnetic torque is expressed as:

$T_{e m}=\frac{3}{2} * \frac{P}{2}\left(\varphi_{d s *} i_{q s}-\varphi_{q s} i_{d s}\right)$

Where: $v_{\mathrm{ds}}, v_{\mathrm{qs}}:$ Stator Voltages in D-Q axis reference Frame $,{ }^{v} d r,{ }^{v} q r$ :Rotor Voltages in D-Q axis reference Frame, ${ }_{i d s}, i_{q s}:$ Stator Currents in D-Q axis reference Frame $i_{d r}, i_{q r}$ : Rotor Currents in D-Q axis reference Frame $, \phi_{d s}, \phi_{q s}$ :Stator Flux Linkages in D-Q axis reference Frame, $\phi_{d r}, \phi_{q r}$ : Rotor Flux Linkages In D-Q Axis Reference Frame ${ }, Q_{S}, Q_{S}:$ Stator Active, Reactive Power $, P_{r}, Q_{r}$ : Rotor Active, Reactive Power $, R_{s}, R_{r}$ : Stator and Rotor Resistance per phase $, \omega_{e}, \omega_{r}$ : Supply and Rotor Flux Angle $, L_{S}, L_{r}$ : Stator and Rotor Inductance

$L_{l s}, L_{l r}, L_{m}$ :Stator, Rotor Leakage Inductance, and Magnetizing

Inductance, and $T_{e}:$ Electromagnetic Torque.

The control of doubly fed induction generator with wind turbine is necessary and unavoidable. The control system maintains magnitudes of the generator, such as torque, active and reactive power, related to the grid side converter. The reactive power and the DC bus voltage close to their optimum values, for proper and effective energy generation [15-20].The Control schemes of DFIG based wind turbine will be described in details in the following sections.

\section{CONTROL OF THE ROTOR SIDE CONVERTER}

The control strategy for the rotor side converter is shown in Fig.5. The active power flow is controlled through $i_{d r}$ and the reactive power flow is controlled through $i_{\text {qr }}$. The standard voltage oriented vector control strategy is used for the rotor side converter to implement control action. Here the real axis of the stator voltage is chosen as the d- 
axis [11]. The actual speed of the turbine $\omega_{\mathrm{r}}$ is measured and the corresponding mechanical power of the tracking characteristic is used as the reference power for the power control loop.The actual electrical output power, measured at the grid terminals of the wind turbine is added to the total power losses (mechanical and electrical) and is compared with the reference power obtained from the tracking characteristic.

A Proportional-Integral (PI) regulator is used to reduce the power error to zero. The output of this regulator is the reference rotor current $\mathrm{I}_{\mathrm{dr} \_ \text {ref }}$ that must be injected in the rotor by the converter. This is the current component that produces the electromagnetic torque $\mathrm{T}_{\mathrm{em}}$. The actual $\mathrm{I}_{\mathrm{dr}}$ component is compared to $\mathrm{I}_{\mathrm{dr} \_ \text {ref }}$ and the error is reduced to zero by a current regulator (PI). The output of this current controller is the voltage $\mathrm{V}_{\mathrm{dr}}$ generated by control of the rotor side converter. The current regulator is assisted by feed forward terms which predict $\mathrm{V}_{\mathrm{dr}} . \mathrm{I}_{\mathrm{q} \text { ref }}$ is set zero obtain zero reactive power as shown in Fig.5 [17-22].

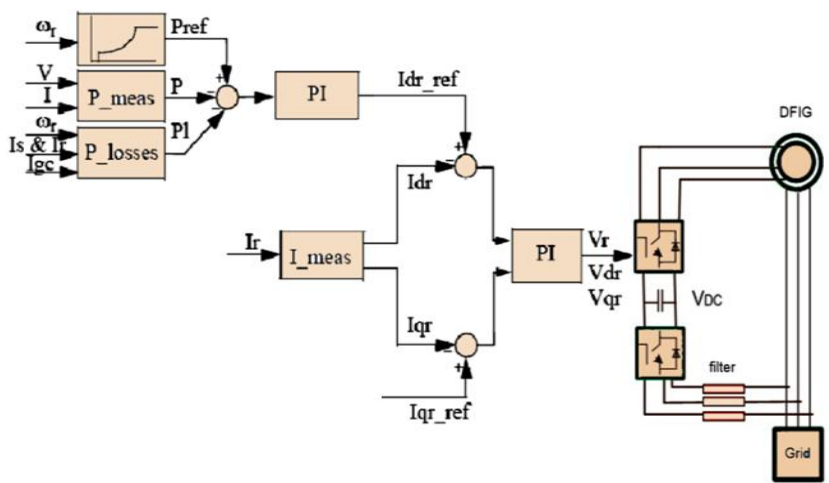

Fig.5: Vector control structure of rotor side converter.

\section{CONTROL OF THE GRID SIDE CONVERTER}

The main objective of the grid side converter is to maintain the DC - link voltage constant for the necessary action. For the grid-side controller, the d-axis of the rotating reference frame used for $\mathrm{d}-\mathrm{q}$ transformation is aligned with the positive-sequence of grid voltage. The control system is shown in Fig.6. This controller consists of; (1) Measurement system which measures the d and q components of AC currents to be controlled as well as the DC voltage $V_{d c}$, (2) Outer regulation loop consisting of a DC voltage regulator. The output of the DC voltage regulator is the reference current $I_{d g c r e f}$ for the current regulator $\left(I_{\mathrm{dgc}}=\right.$ current in phase with grid voltage which controls active power flow).(3) An inner current regulation loop consisting of a current regulator. The current regulatory controls the magnitude and phase of the voltage generated by converter from the $I_{\text {dgc } \_r e f}$ produced by the DC voltage regulator and specified $\mathrm{I}_{\mathrm{q} \_ \text {ref }}$ [10], and [22-24]. The DC link voltage can be expressed as:
$C \frac{d_{v_{d c}}}{d t}=\frac{3}{4} m i_{g d c}-i_{r d c}$

Where $i_{\text {gdc }}$ is the $d$-axis current flowing between the grid and the grid side converter, $i_{\text {rdc }}$ is the rotor side DC current, $\mathrm{C}$ is the DC link capacitance; $\mathrm{m}$ is the PWM modulation index of the grid side converter. The reactive power flow into the grid $\mathrm{Q}_{\mathrm{g}}$ is calculated as

$Q_{g}=\frac{3}{2}\left(V_{g} i_{g q}\right)$

Where $\mathrm{V}_{\mathrm{g}}$ is the magnitude of the grid phase voltage, $\mathrm{i}_{\mathrm{qg}}$ is the q-axis current flowing between the grid and the grid side converter. From eq. (20) and eq.(21), the DC link voltage and the reactive power flow into the grid can be controlled via $i_{\mathrm{gq}}$.

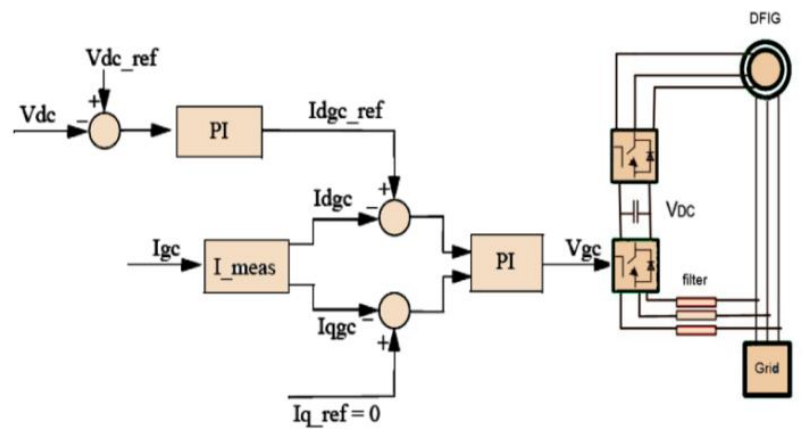

Fig.6: Vector control structure of Grid side Converter.

\subsection{Optimal torque (OT) control (sensor)}

As mentioned previously, maintaining the operation of the system at $\lambda_{\text {opts }}$ ensures the conversion of available wind energy into mechanical form. It can be observed from the block diagram in Fig.7 [15] that the principle of this method is to adjust the DFIG torque according to a maximum power reference torque of the wind turbine at a given wind speed. For the turbine power to be determined as a function of $\omega_{\mathrm{m}}$, the following equation will be adopted in order to obtain the wind speed [2026]:

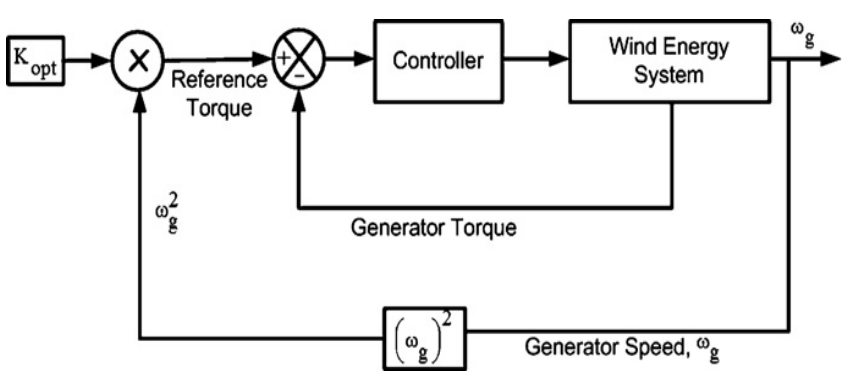

Fig.7. The block diagram of optimal torque control for MPPT control. 
Using eq.(1) \& (3), the output optimum power wind turbine can by written as

$$
\mathrm{P}_{\mathrm{m}_{-} \mathrm{opt}}=0.5 \rho \mathrm{AC} \mathrm{C}_{\mathrm{p}-\mathrm{opt}}\left(\frac{\omega_{\mathrm{m}-\mathrm{opt}} \mathrm{R}}{\lambda_{\mathrm{opt}}}\right)^{3}
$$

Where

$$
\begin{gathered}
\mathrm{K}_{\mathrm{opt}}=0.5 \rho \mathrm{AC}_{\mathrm{p}-\mathrm{opt}}\left(\frac{\mathrm{R}}{\lambda_{\mathrm{opt}}}\right)^{3} \\
\mathrm{P}_{\mathrm{m}-\mathrm{opt}}=\mathrm{K}_{\mathrm{opt}}\left(\omega_{\mathrm{m}-\mathrm{opt}}\right)^{3}
\end{gathered}
$$

Consider that $\mathrm{P}_{\mathrm{m}}=\mathrm{T}_{\mathrm{m}} * \mathrm{~W}_{\mathrm{m}}$

$\mathrm{T}_{\mathrm{m}-\mathrm{opt}}=\mathrm{K}_{\mathrm{opt}}\left(\omega_{\mathrm{m}-\mathrm{opt}}\right)^{2}(25)$

Fig. 3 indicates the mechanical power generated by the turbine as a function of rotor speed for different wind speeds. The maximum power extraction within the allowable range can be achieved if the controller can properly follows the optimum curve with variation of wind speed.

\subsection{Sensorless Wind Speed Estimation Technique}

From eq.(1),(3), and (27) wind speed can be estimated if the value of mechanical power and power coefficient which is a function in rotor speed and wind speed are known. Eq. (28) governs the estimated wind speed. Fig.8 shows representation of eq.(29).

$$
\begin{gathered}
\zeta=\frac{p_{m}}{p_{e}} \text { (26) } \\
\frac{p_{e}}{\xi}=\frac{1}{2} \rho A C_{p} V_{w}^{3} \\
\boldsymbol{V}_{\boldsymbol{w}}=\sqrt[3]{\frac{\boldsymbol{P}_{e}}{\xi * C_{p} * K_{\text {opt. }}}}(28) \\
\mathbf{V}_{\mathbf{w}}=\left(\frac{\mathbf{P}_{\mathbf{e}}}{\mathbf{0 . 5 \rho A}_{\mathbf{p} \boldsymbol{\eta}}}\right)^{\frac{1}{3}}(29)
\end{gathered}
$$

To estimate the wind speed from eq.(26), the efficiency $\eta$ of the DFIG is assumed to be equal to $92 \%$ and losses converter are neglected

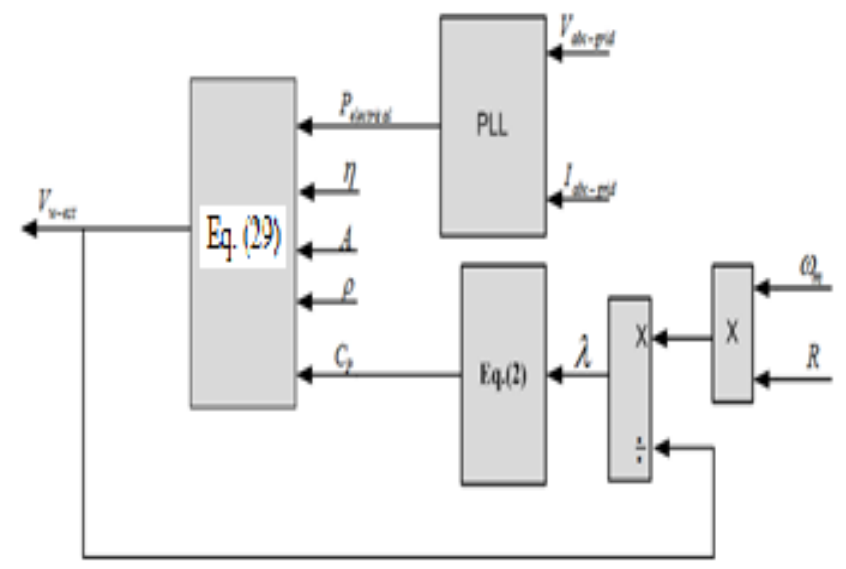

Fig.8 Estimated wind speed block diagram

\section{Simulation Results and discussion}

The parameters of the system under study are given in appendix A. MATLAB/SIMULINK software is used to perform the simulation using power system block sets with a simulation time of 1.5 seconds. The proposed control scheme for DFIG based variable speed WECS is simulated using MATLAB/Simulink under different cases for wind speed variations.

\section{Case study no.1:}

Fig.9.shows The wind speed profile, which varies up and down with smooth ramp rates, with average value 11.05 $\mathrm{m} / \mathrm{s}$. further wind speed is estimated.

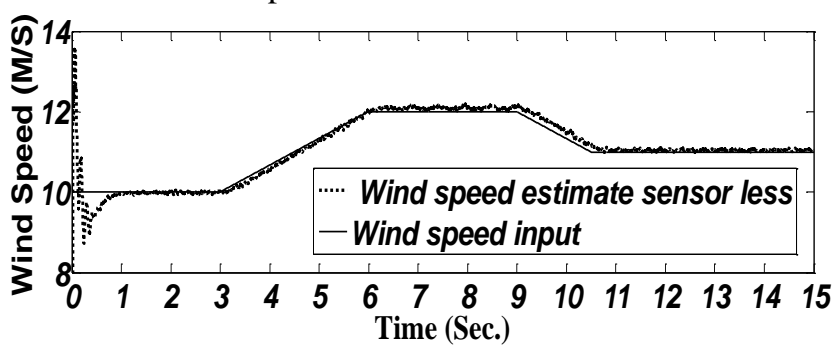

Fig.9 Ramp change in actual wind speed \& estimated wind speed in $\mathrm{m} / \mathrm{s}$.

Results shows that sensor less control have beter performance than sensor type control. As seen from Fig.10 The maximum power capture is achieved, hence the tip speed ratio $\lambda$ achieve the optimality $(\lambda=8.1)$ and $C p$ is constant at maximum value $(\mathrm{Cp}=0.48)$.

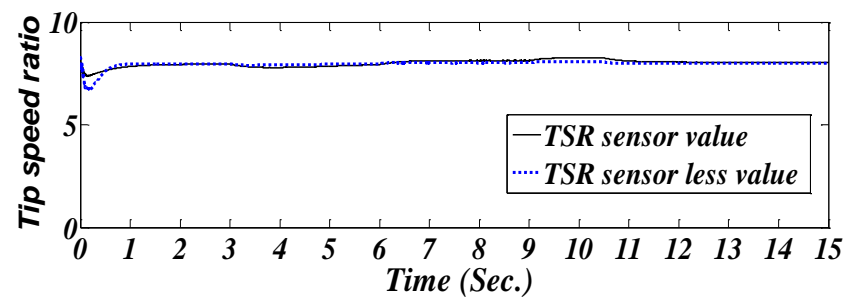

(a)

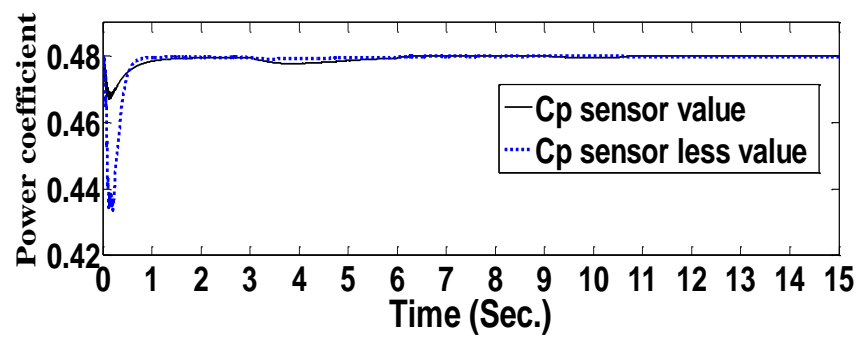

(b)

Fig.10 (a) Tip speed ratio $\lambda$ (b) power coefficient Cp.

Fig.11andFig.12 shows the impact of control system on rotational speeds of generator, mechanical torques curve with same determination oriented electrical torque result of 
lack of gear box.which clearly shows that it takes the same wind speed profile except at sudden change where the moment of inertia appeared.

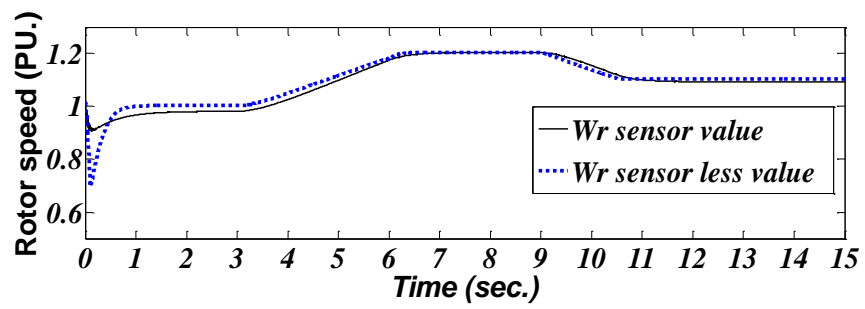

Fig.11 Rotational speed of the generator.

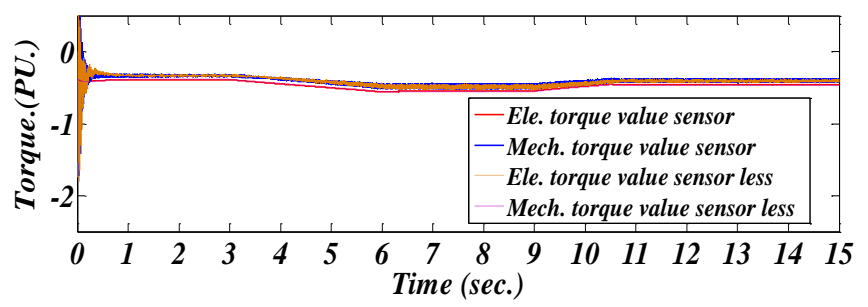

Fig.12 Mechanical \&electrical torque of the generator.

Fig.13 (a) and (b) illustrate the grid active and reactive power respectively. As shown in Fig.13(a), the control system used achieve that power injected to the grid is varied with wind speed variation and the reactive power injected to the grid is zero(i.e. unity power factor) as shown in Fig.13 (b).

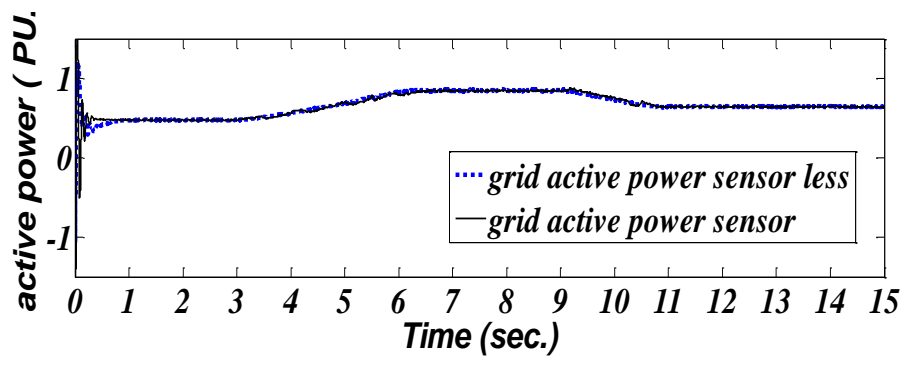

(a)

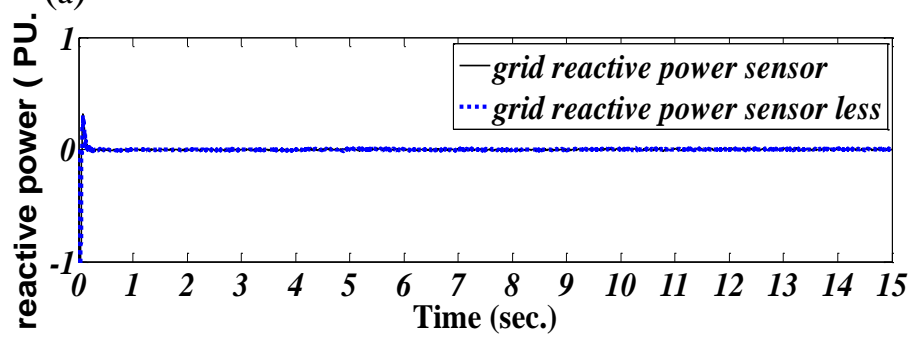

(b)

Fig.13 (a) Grid active power. (b) Grid reactive power.

From Fig.14, the Dc-link voltage ripple is reduced $\left(\mathrm{VDC} \sim \mathrm{V}_{\text {ref }}(1200 \mathrm{v})\right)$ and almost constant over the all period of simulation time.

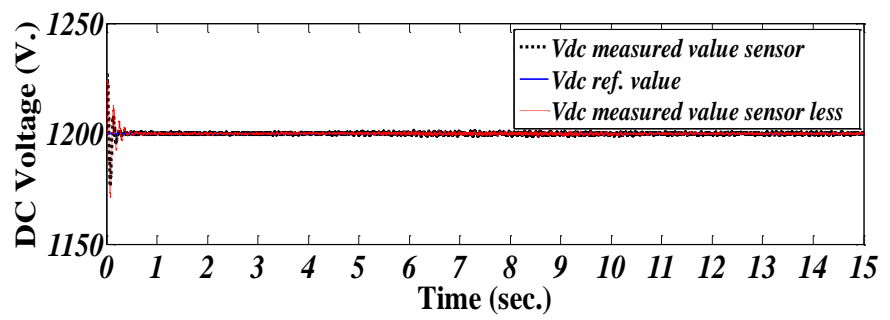

Fig.14 DC link voltage in Volt.

\section{Case studv no.2}

The wind speed profile varies randomly with mean value of $10 \mathrm{~m} / \mathrm{s}$ and $20 \%$ turbulence intensity according to wind model . further wind speed is estimated of Wind Turbine Block set in Matlab/Simulink [27] as shown in Fig.15.

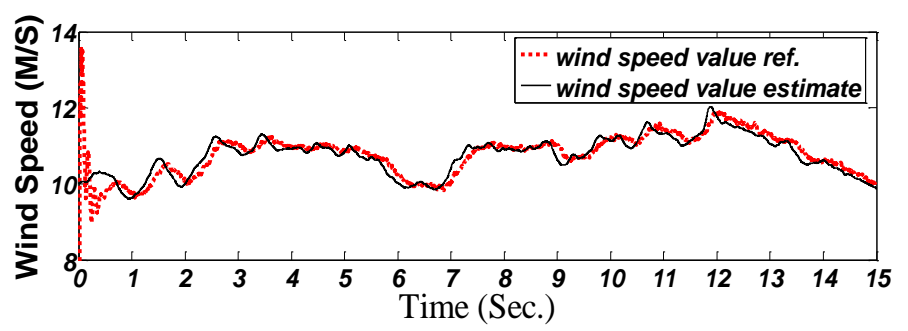

Fig.15 Random change in wind speed \& wind speed estimate in $\mathrm{m} / \mathrm{s}$.

Fig.16, and Fig.17 show the impact of control system on rotational speeds of generator, mechanical torques curve with same determination oriented electrical torque result of lack of gear box. which clearly shows that it takes the same wind speed variation.

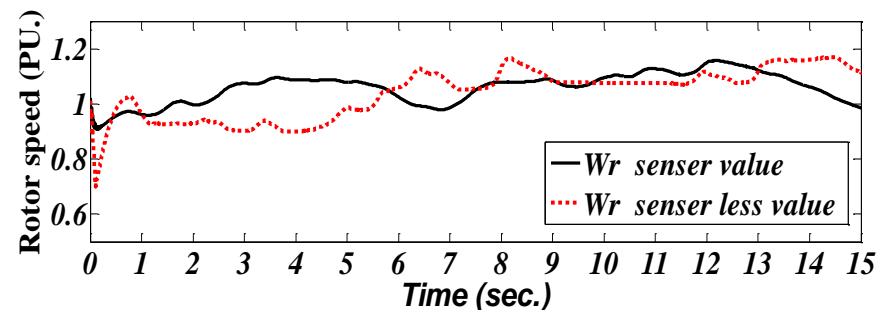

Fig.16 Rotational speed of the generator.

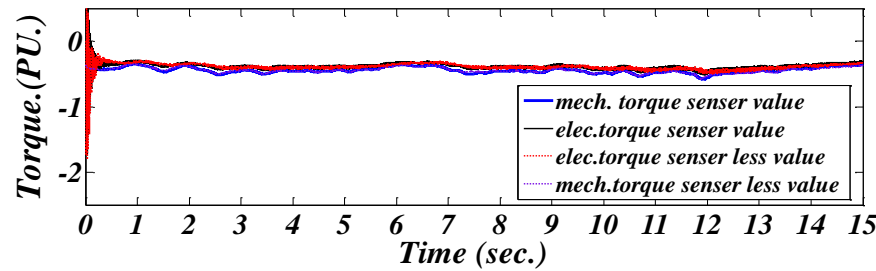

Fig.17 Mechanical\&Ele. Torque of the generator.

As shown in Fig.18 (a) and (b) respectively the control scheme of the rotor side converter gives beter performance using sensor, and senser less MPPT control scheme for DFIG. The maximum power capture is achieved, hence the tip speed ratio $\lambda$ achieve the 
$\operatorname{optimality}(\lambda=8.1)$ and $\mathrm{Cp}$ is constant at maximum value $(\mathrm{Cp}=0.48)$.

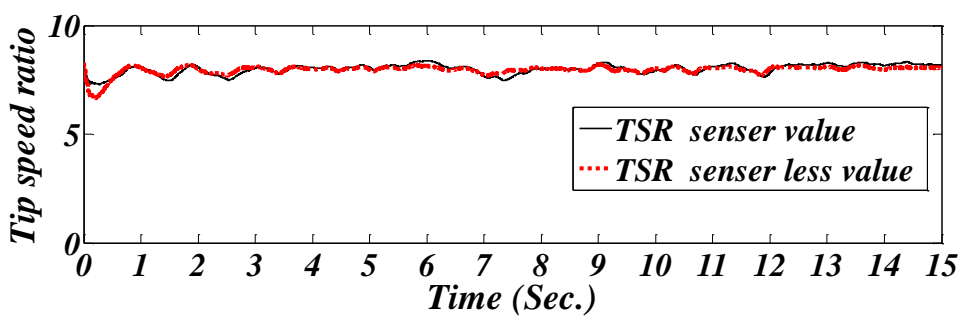

(a)

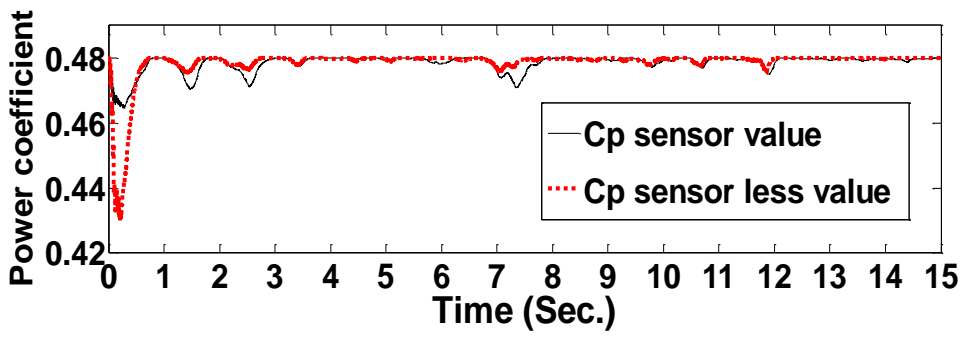

(b)

Fig.18 (a) Tip speed ratio $\lambda$ (b) power coefficient $\mathrm{Cp}$.

$I_{d}$ and $I_{q}$ are shown in Fig.19, Id varied with wind speed and $\mathrm{Iq}=0$.

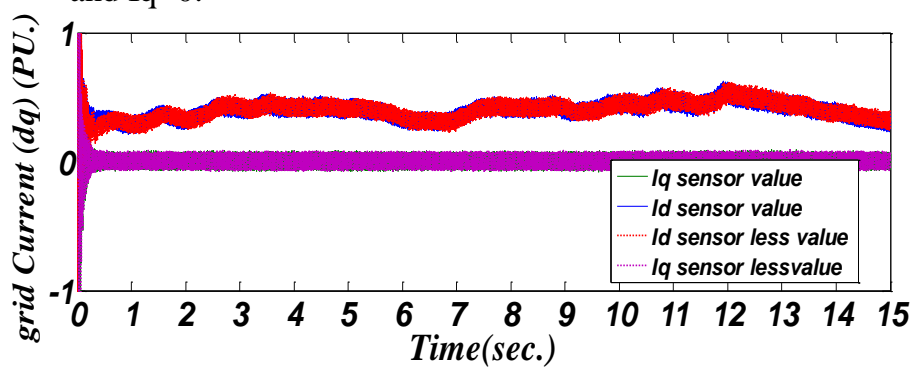

Fig. 19 grid Current $I_{d}$ and $I_{q}$

In Fig.20 (a) and (b) the grid active power and grid reactive power is discussed respectively where the reactive power is nearly zero, hence unity power factor is achieved. control system used achieve that power injected to the grid is varied with wind speed variation and the reactive power injected to the grid is zero.

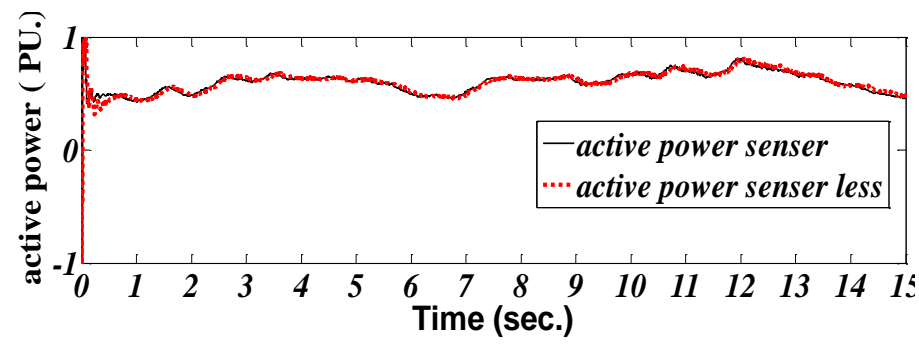

(a)

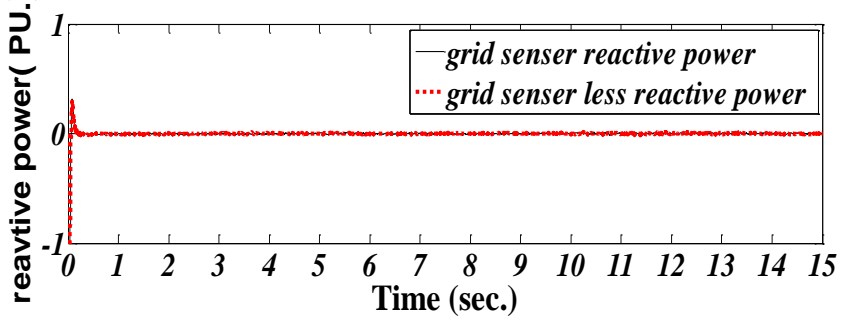

(b)

Fig.20 (a) Grid active power in pu (b) Grid reactive power.

The DC link voltage is nearby constant (VDC Vref $(1200 \mathrm{v}))$ over the all period of simulation time by using grid side converter as seen in Fig.21.

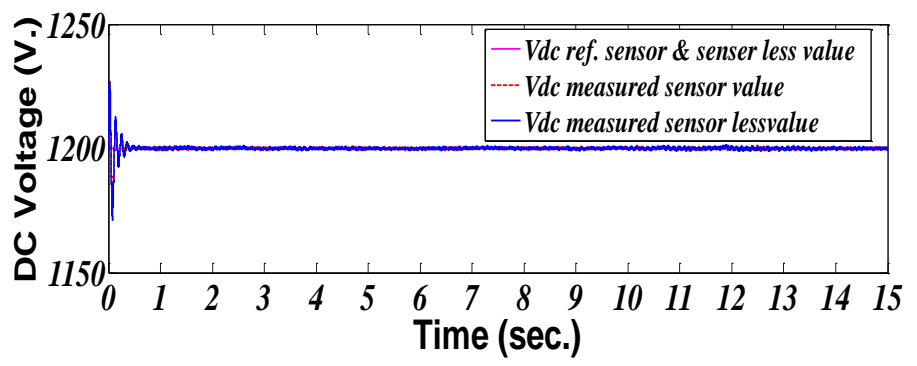

Fig.21 DC link voltage in Volt.

\section{CONCLUSION:}

This paper has presented a comprehensive modeling of direct driven DFIG based grid-connected wind turbines along with control schemes of the interfacing converters. Grid powerhas been achieved based on the injected wind velocity estimationin addition to the system efficiency.

Three-phase interface power converter based on back-toback common dc-link converter has been used to achieve the system objectives. The generator side converter based three-phase has been used to achieve maximum power operation point at each wind speed. The grid side converter based three-phase has been used to inject sinusoidal current in-phase with the grid voltage in addition to controlling the common dc-link capacitor voltage. Vector current controller has been employed on the grid side VSI to obtain unity power factor. Simulation results prove that the proposed control scheme has a great capability to obtain unity power factor at the grid side and to achieve sensorless maximum power point tracking of wind turbine based onDFIG during wind speed variation.

Results show that sensorless control gives better performance than sensor type control. Sensorless control manage to trace the variations in wind speed. 


\section{REFERENCES}

[1] Committee on Environmental Impacts of Wind Energy Projects, "Environmental Impacts of Wind Energy Projects", Washington, The National Academies Press, 2007.

[2] Report of New and Renewable Energy Authority, available on line at http://www.nrea.gov.eg last access 20 Oct 2014.

[3] Thongam, Jogendra Singh, and Mohand Ouhrouche. "MPPT Control Methods in Wind Energy Conversion Systems", available online at http://www.intechopen.com last access 22 Oct 2014 [4] Acharya, Parash, "Small Scale Maximum Power Point Tracking Power Converter for Developing Country Application", Master of Engineering, University of Canterbury, Christchurch, New Zealand. (2013).

[5] Ali H. Kasem Alaboudy, Ahmed A. Daoud, Sobhy S. Desouky, and Ahmed A. Salem, "Converter Controls and Flicker Study of PMSG- Based Grid Connected Wind Turbines", Ain Shams Engineering Journal, Elsiever, vol. 4, issue 1, pp. 75-91, Mar. 2013.

[6] M. Chinchilia, S. Arnaltes, and J. Burgos, "Control of Permanent- Magnet Generator Applied to Variable- Speed Wind -Energy Systems Connected to the Grid," IEEE Trans. Energy Conversion, vol. 21, no.1, Mar. 2006

[7] S. Muller, M. Deicke, and R. W. De Doncker, "Doubly fed induction generator systems for wind turbines," IEEE Ind. Appl. Mag., vol. 8, no.3,pp. 26-33, May/Jun. 2002.

[8] K.Tan, and S.Islam, "Optimum Control Strategies in Energy Conversion of PMSG Wind Turbine System without Mechanical Sensors," IEEE Trans. Energy Conversion, vol.19, no.2, Jun. 2004.

[9] Ahmed A. Daoud, Sobhy S. Dessouky, and Ahmed A. Salem, "Control Scheme of PMSG Based Wind Turbine' for Utility Network Connection," in 10th EEEIC Proc., Rome, Italy, May 8-10, 2011.

[10] Abdullah, M. A., A. H. M. Yatim, C. W. Tan, and R. Saidur, "A review of maximum power point tracking algorithms for wind energy systems" Renewable and Sustainable Energy Reviews 16, no. 5 (2012): 32203227.

[11] M.H. Elfar,"Maximum Power Tracking Algorithm for Wind Energy Systems Based on Artificial Intelligence", PHD theses, Suez Canal University,2010.

[12] G. Podder, A. Joseph, and A. Unnikrishnan, "Sensorless Variable-Speed Controller for Existing FixedSpeed Wind Power Generator with Unity-Power-Factor Operation”, IEEE Trans. Ind. Electron., Vol. 50, No. 5, pp.1007-1015, Oct. 2003.

[13] Francoise Mei and Bikash Pal, "Modal Analysis of Grid-Connected Doubly Fed Induction Generators", IEEE
Transactions on Energy Conversion, Vol. 22, No.3, pp. 728-736, September 2007.

[14] Xin Jing," Modeling And Control Of A Doubly Fed Induction Generators for Wind Turbine Generator Systems", Master theses, Marquette University, December 2012.

[15] Alireza Abbaszadeh, Saeed Lesan and Vahid Mortezapour, "Transient Response of Doubly Fed Induction Generator Under Voltage Sag Using an Accurate Model", 2009 IEEE PES/IAS Conference on Sustainable Alternative Energy (SAE), pp. 1-6, September 2009.

[16] Abdullah MA, Yatim AHM, Tan CW. "A study of maximum power point tracking algorithms for wind energy system", 2011 IEEE, first conference on clean energy and technology (CET). 2011. p. 321-6.

[17] R. Data and V. Ranganathan, "A Method of Tracking the Peak Power Points for a Variable Speed Wind Energy Conversion System", IEEE Trans. Energy Conversion, Vol. 18, No.1 pp.163-168, Mar.2003.

[18] Q. Wang, L. Chang, “An Intelligent Maximum Power Extraction Algorithm for Inverter-Based Variable Speed Wind Turbine System," IEEE Trans. Power Electronics, Vol. 19, No. 5, pp.1242-1249, Sept. 2004.

[19] W.M.Lin, C.M. Hong, and F.S.Cheng, "Fuzzy neural network output maximization control for sensor less wind energy conversion system," Energy, vol. 35, no. 2, pp. 592601, Feb. 2010.

[20] J.S.Thongam,P.Bouchard, H. Ezzaidi and M.Ouhrouche, "Artificial Neural Network Based Maximum Power Point Tracking Control for Variable Speed Wind Energy Conversion Systems," in proc. of IEEE MSC2009, July 8-10,2009.

[21]M.M.Hussien, M.Orabi,Mahrous.E.Ahmed, and M.A.Elwahab, "Simple direct sensorless control of permanent magnet synchronous generator wind turbine," in Proc. of 14th international Middle East Power System Conf. (MEPCON'10), Cairo university, Egypt., Dec.1921,2010 .

[22] Anca D. Hansen, Florin Iov, Poul Sørensen, Frede Blaabjerg, "Overall control strategy of variable speed doubly-fed induction generator wind turbine," Nordic Wind Power Conference, 1-2 Mar. 2004.

[23] F. Mei and B. Pal, "Modal Analysis of GridConnected Doubly Fed Induction Generators", IEEE Trans. on Energy Conversion, Vol. 22, No. 3, September 2007, pp. 728-736.

[24] L. Xu, and Y. Wang, "Dynamic Modeling and Control of DFIG -BasedWind Turbines Under Unbalanced Network Conditions", IEEE Transactions on Power Systems, Vol. 22, No.1, February 2007, pp. 314-

323.

[25] A. H. Kasem Alaboudy, "Power conditioning and performance enhancement of wind based distributed generation," PhD thesis, Minia University, 
Egypt, 2009.

[26] Ion Boldea, "Variable speed generators" (Electric power engineering series). Publ.CRC 2005.

[27] F .Iov, A. D. Hansen, P. Sorensen, and F.Blaabjerg, "Wind Turbine Blackest in Matlab/Simulink, Research Project", Institute of Energy Technology, Alborg University, Mar. 2004.

\section{Appendix d . PI parameters}

Rotor .side current loop: $\mathrm{K}_{\mathrm{p}} \quad 0.3$

Grid side current loop:-

$\mathrm{K}_{\mathrm{i}} \quad 8$

$\mathrm{K}_{\mathrm{p}} \quad 0.44$

Dc-link loop:-

$\begin{array}{ll}\mathrm{K}_{\mathrm{i}} & 0.008\end{array}$

Appendix A. Specification of wind turbine

The coefficients $\mathrm{C}_{1}$ to $\mathrm{C}_{6} \quad C_{1}=0.5167$

$\mathrm{K}_{\mathrm{p}}$

$$
\begin{array}{cc}
C_{2}=116 & C_{3}=0.4 \\
C_{4}=5 & C_{5}=21 \quad C_{6}=0.0068
\end{array}
$$

\section{Appendix D. MATLAB/SIMULINK}

Wind turbine blade radius $R=1.8 \mathrm{~m}$

Air density

$$
\rho=1.25 \mathrm{~kg} / \mathrm{m}^{3}
$$

Optimal tip speed ratio

$$
\lambda_{\text {opti }}=8.1
$$

Maximum

power

$C_{p-\max }=0.48$

Coefficient

\section{Appendix B. Parameter of IG}

Stator phase resistance $\left(\mathrm{R}_{\mathrm{s}}\right)$

Stator direct inductance $\left(\mathrm{L}_{\mathrm{d}}\right)$

Rotor phase resistance $\left(\mathrm{R}_{\mathrm{r}}\right)$

Rotor direct inductance $\left(\mathrm{L}_{\mathrm{d}}\right)$

No. of pole pairs $(\mathrm{P})$

Inertia of the whole system (J)

Friction factor (B)

\section{Appendix C. DC bus and gird parameters}

dc-link voltage

$$
\mathrm{V}_{\mathrm{dc}}=1200
$$

Capacitor of the dc-link

$$
\mathrm{C}=6 \mu \mathrm{F}
$$

Grid frequency

$$
\mathrm{F}=50 \mathrm{hz}
$$

Grid resistance

$$
\mathrm{R}_{\mathrm{g}}=0.02 \Omega
$$

Grid inductance
$0.023 \mathrm{PU}$

$0.18 \mathrm{PU}$

$0.016 \mathrm{PU}$

$0.16 \mathrm{PU}$

3 pair pole 0.0095 N.m

$0.05479 \mathrm{PU}$

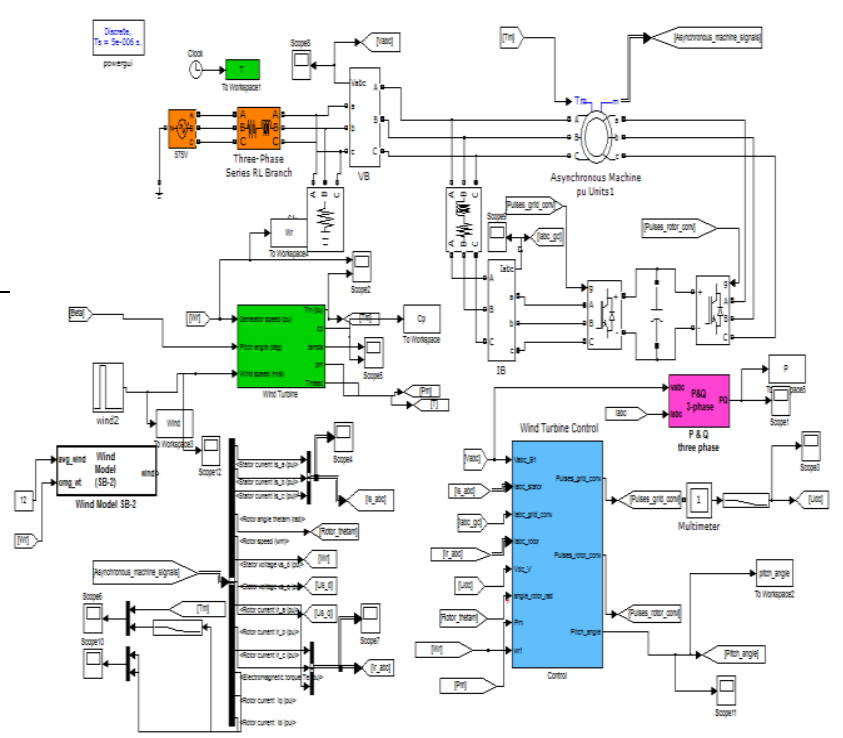

Fig..22.Simulation scheme of a 1.5 MW doubly-fed induction generator wind turbinegenerator system.

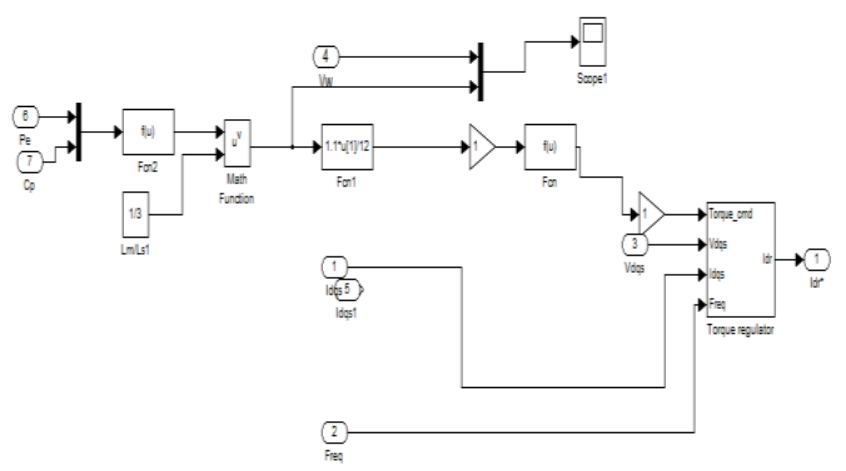

Fig.23 Simulation scheme Control Current 